\title{
The Research-Based Learning Teaching Model in the University Physical Culture Teaching based on Local Fractal Theory
}

\author{
Yanni $\mathrm{Li}^{*}$ \\ Wuchang Institute of Technology, Wuhan, Hubei, China
}

\begin{abstract}
This paper studies the research-based learning teaching model in the university physical teaching based on local fractal theory. The Research-based learning teaching model is innovative and has been extensively applied in the course teaching of universities and middle schools at home and abroad. From the correlation theory in characteristics of university teaching and research-based teaching model, we can see that it is necessary and feasible to apply this new model in university teaching. This is also proved by the tentative application in the course Network Marketing. The only way to cultivate more excellent for the social is usefulness of talent.
\end{abstract}

Keywords: Application, kernel functions, local fractal theory, research-based learning teaching model, university physical teaching.

\section{INTRODUCTION}

The $21^{\text {st }}$ century is a knowledge-economic era characteristic of creativity and application of knowledge, and frequency of creativity and application of knowledge is constantly quickened, updating period of knowledge is shorten. In order to update one's own knowledge constantly to keep pace with drastic change and competition in the society, it is very important to possess the ability of "being able to work learn and research". Effective means of cultivating this consciousness and ability is project-based learning. Projectbased learning means that students choose and determine project to research from nature social and livelihood with teachers guide, and drivingly procure knowledge, apply knowledge and solve concrete problem. This learning method has three major functions: cultivating open individuality and an insight into future, activating inquiring interesting and creative consciousness and shaping down-to-earth spirit and operating ability. Project-based learning is not only the call of times but also the necessary historic certainty. As an important means and carrier in educating students' creative consciousness and practical ability, project-based learning is undoubtedly a hot spot, a difficult point and a sparking point in basic education reforming. The author thinks that we should also appreciate Project-based learning in higheducation that is the base of person-training.

Project-based learning is opposite to acceptance-based learning. As far as development for man is concerned, the both are necessary, and they complement each other and happen at the same time during the concrete activity of man which is defined by the theory.

Because they excessively depended on acceptance-based learning in the past, so the students can not great but only accept, which means shortage of capacity for individuality and losing power that progress depends on for country, especially the students who are fostered in Chinese traditional education should appreciate project-based learning. Research study teaching model mainly refers to students in real-life situations in the open, through experience and learning to solve problems conscious, under the guidance of teachers, and identify research topics selected from the study of life or social life, personal or cooperative group study conducted in a manner, the initiative to acquire knowledge, apply knowledge to solve problems. Research-based learning, also called inquiry learning, is brought up by Professor Schwab [1] in 1950s in "education of the model movement". He believes that the learning process of students and research scientists in the process is essentially the same. Therefore, students should like scientists to discover the identity of the owner to solve problems, and to acquire knowledge and develop skills in the course of the study, training capacity [2].

In the past ten years, Local fractional calculus $[3,4]$ has been widely applied to many fields such as mathematics, image processing and signal processing etc. Some authors have given many definitions of local fractional derivatives and local fractional integrals (also called fractal calculus) [5]. Hereby we rewrite the following local fractional derivative which is given by [6].

The traditional teacher-cantered teaching mode is not in favour of training students' independence and creativity. Popularizing the research study and having researchstudying curriculums are just catering to the need of training creative person with ability.

The research study is that students directed under teachers choose and establish research themes, take research activities by themselves, synthesize what they have grasped to get new knowledge, train the ability of analysing and solving problems and of creativity. As a new kind of study mode, the research study has characters, such as independence, open- 
ing, integration, process and collectively. This paper has expounded the significance of the research study, characters, the source and development of the research theme, the goal, the implementation methods and evaluating ways, and so on.

Research study and research study teaching are always resorting to information technique. The function and practice of information technique during the course of research study activities are expounded in this paper. The Vocation character, the student character and other things must be known during the course of research study activities in the highlevel vocation school, so this paper expounds the education character and education object in the high-level vocation school education, paves the way for how to take research study activities by students in the high-level vocation school.

Through research study activity practice in physical teaching along with author's teaching experience in more than ten years, the paper expounds many kinds of ways and means applied in physical teaching, such as physics class, physical demonstrated experiment, student experiment, and experiment after school and so on. At the same time this paper expounds in detail the practice course in the research study activity directed by author in physical teaching.

This paper expounds demands for teachers in research study activity in brief, problems that need to be paid attention to and corresponding measures for them. The research goal of this paper is to explore what research study styles fit students in the high-level vocation school, taking research methods through theory research along with teaching practice。 According to the demands of research study, a lot of teaching practices of research study are taken, physics research study activities for students in the high-level vocation school are designed alone and performed, the things mentioned is helpful and used for reference for research study activities taken in the high-level vocation school [7].

\section{THE ORIGIN OF THE RESEARCH STUDY}

In the background of knowledge economy and a time calls for innovation, to construct an innovative country has become an important strategy in national polices. Being the main subject of innovative research and regional innovation system, research universities are playing a crucial role in innovating knowledge and incubating experts. Accompany with the aim raised by the Nation of building a certain amount of high quality research universities and encouraging collaborative innovation among such institutes, universities have paid more attention on improving the ability of innovation and scientific research as to achieve such goal. Although innovation and research are two hot issues that are greatly concerned by the universities' management, they are still the blind spots of designers and builders. Little study was carried out on the characteristics of research universities and innovation activities in campus, and it has resulted in that the theoretical guidance is far behind the construction needs of building research universities [11].

As early as the fifties and sixties, the cognitive theory of discovery learning, constructivism learning theory and constructivism learning theory advocated by Brunerare the research study provides a rich theoretical basis [8]. In Bruner view, access to knowledge regardless of its form, is expressed as a positive cognitive process. In this process, the learner is an active inquiry, teachers need to do is to provide learners with a way to independently explore the context of learners, rather than ready-made knowledge.

Human learning theory that human beings have a natural desire to learn and potential, which is a psychological tendency trusted, they can be released under appropriate conditions. Teacher's task is not to teach the students the knowledge, nor is it a means of teaching students how to learn, but to provide learning for the students should learn how to as you should be decided by the students themselves, the teacher's role should be student learning "facilitator." When students understand their own learning content and relevant to the needs, they are motivated to learn most easily excited, in a psychological sense of security with a better learning environment $[9,10]$.

Constructivist learning theory is that knowledge is not taught by teachers get, but learners that under certain situations the social and cultural background, with other people (including teachers and learning partners) to help with the necessary learning materials, through the construction of meaning way to obtain. Because learning is that social and cultural backgrounds certain situations, with the help of others sense that through collaborative activities interpersonal achieved construction process, so constructivist learning theory that "situation", "collaboration", "session" and "construction of meaning" is the four elements of the learning environment. Constructivism advocated under the guidance of teachers, learner-centred learning. Students are the subject of information processing is active construction of meaning, rather than passive recipients of external stimuli and infused objects.

With the coming of information age, information technologies signed as multimedia and network has offered the essential realization means for the learning by inquiry. The information technology is means to gathering, processing, storing, exchanging, technology using and system of the method to the information. Information can satisfy the needs of learning by inquiry fully, because it has such characteristics as a great deal information resources, synchronism asynchronous exchange way, quick feedback and etc.

Through learning history and analysing current situation, the writer realizes that learning by inquiry is an educational development theme of our times. Information technology can provide cogent help for the students on finding problem, collecting information, dealing with information, using information, mutual aiding and etc. It also can provide help for the teachers on guiding students effectively, encouraging students the interest of study, encouraging students to study and participating in student's evaluation in their study course. But the discussion in the theory aspect is relatively more in existing research quality of learning by inquiry, while the discussion aspect on operating is fewer, especially fewer on the actual operation problem occurs when the primary and middle school teacher is teaching. Although the importance of information technology during learning by inquiry has been certain understood, it is seldom referred how to use and what the result is. In the course of learning by inquiry, student should grasp the technical ability of the information expertly instead of the application enthusiasm of the information technology. The teacher should change one's own 
concept constantly, meet new change of new study way at the educational theory and teaching behaviour and improve one's own information technology training constantly; School and responsible educational administrative department should offer essential hardware environment and software environment for the developments of the new study way. Teachers and students' rate should be reduced. It should be changed to appraise the system. The resource construction of teaching should be concerned. The teacher's information training should be improved.

\section{NECESSITY AND FEASIBILITY OF RESEARCH STUDY TEACHING MODEL IN UNIVERSITY PHYSICAL CULTURE TEACHING}

The research study teaching model for converting university teaching philosophy, and improve the teaching system and promote the reform of university teaching, promoting the employment of university students and others have practical significance. Out of the many colleges and universities to explore the application model also proved that the research study teaching model in the ascendant, in practical application in line with the characteristics of university teaching, in line with the basic ideas of teaching reform, adapt to the development direction of university teaching. Currently, the research study has become an international education sector generally respected and implemented a teaching model, teaching in primary schools, secondary schools, universities and all disciplines at all stages of the course are to a certain degree of promotion. Since 1983, the University of Texas at Austin, the two MBA students organized the first business plan competition since the United States has so far include Massachusetts Institute of Technology, Stanford University and other world-class universities, including more than 20 universities in organizing this event every year.

Statistics show that 50 of America's most outstanding high-tech companies, $46 \%$ is from the Massachusetts Institute of Technology's business plan competition. Tsinghua University in China in 1999 held the first "Challenge Cup" Chinese university student entrepreneurship competition held successive successful universities in the country launched an innovative, entrepreneurial boom. Ministry of Education in January 2000 promulgated the "full-time ordinary high school lesson plans (experiments revised)" first time "research study" as an important part of "comprehensive practical activities" to be included. 2001 revised the "ordinary high school" research study "Implementation Guide (Trial)", in high school education stage vigorously research study. In university education, colleges and universities currently popular "Entrepreneurship Competition" is one typical application type research study teaching model.

Many university education expertise comes from practice, but the pace of development practice far more than theoretical research, teaching teachers often have to supplement textbook knowledge to enrich the teaching content outside the student in the learning process is often on real life asks the phenomenon, the entire teaching system itself is in a stage of exploration. Research study emphasizes practical teaching model, openness and autonomy and so very helpful in improving the education system in university teaching.
Since the reform of the education system lags behind economic development, leading to train university personnel and business demand for talent disconnect occurs. In recent years, enrolment in colleges and universities on the one hand, on the other hand is difficult for enterprises to procure the right people, the employment rate of college several years of decline, the employment of college students fail every year. Of course, leading talent market supply and demand is not caused by one factor, but in college teaching problem is an important aspect. Throughout our many professional colleges to open e-commerce, both in the teaching process, there are many problems, such as teachers 'own lack of practical management experience in network marketing, how to develop students' practical abilities powerless; improper teaching methods organizations cannot achieve teaching objectives; curriculum obsolete, lack of innovation, curriculum structure is irrational; teaching philosophy behind teacher-centred and "cramming" Teaching is still a dominant position, the lack of advanced teaching model. Research study in the application of teaching model helps to change this situation [12].

\section{THE CONTENT OF THE RESEARCH STUDY TEACHING MODEL AND FRACTAL ALGORITHM}

Research study teaching model is to student-centred teaching, creating a problem situation. Students learning enthusiasm, initiative often filled with questions and problems from the situation. Creation of problem situations, that is, between teaching content and student knowledge psychological create a "mismatch", the students and the issues related to the introduction of a situational process. Through the creation of problem situations so that students clear research objectives, and have a strong desire to study and give thought to power.

Design problem situations when certain issues should reflect the challenging, fun, openness and practicality. Independent study refers to each student based on their own experience, their own way of thinking freely and openly to study the problem and find the problem. Because students learn in the process is an active process of constructing knowledge, rather than passively accepting external stimuli. Based on existing knowledge and experience of students, are based on new knowledge and information processing, comprehension, thereby constructing new knowledge from the network level. Teachers can not replace the student's own thinking, and only through independent thinking [13], independent study, learning in the process of research into knowledge, in order to enable them to experience the joy of acquiring knowledge, thereby enhancing students' selfawareness, spiritual and research students creativity. Cooperation and exchange is the basis of individual students in independent study, so that students in small groups or classes within the scope of collective thinking to fully demonstrate their methods and procedures, mutual discussion and analysis, knowledge of the law and reveal the solution to the problem, ways. Society in cooperation and exchange with each other is to help achieve learning complement and enhance the sense of cooperation, improve communication skills [14].

Research study is a new way of learning, which broke the previous classroom-centred, textbook-centred, teacher- 
centred traditional teaching model. However, the research study teaching model as a new learning and teaching methods, students often can not adapt quickly, they can not clear the purpose and significance of research study, I do not know how to plan arrangements for this form of learning. Therefore, teachers in this learning mode still play an important role. Students conduct research in guiding the learning process, neither can replace the existing model of teaching by students in independent study, not laissez-faire, indifferent. Teachers can use multimedia showcase some of the results of the research study, in order to stimulate students' interest in learning, but also told the students the basic research methods, such as observation, experiment, survey, causal analysis, a comprehensive guide students to carry out inquiry learning. At the end of learning, teachers should help students to analyse the purpose and significance of learning, the learning process as well as a summary of the results of the study and promotion, the only way to achieve the ultimate goal of the research study.

The local fractional algorithm can be expressed as following [15]:

$$
\begin{aligned}
f^{(\alpha)}(x 0) & =\left.\frac{d f(x)}{d x^{\alpha}}\right|_{x=x_{0}} \\
& =\lim _{\delta x \rightarrow 0} \frac{\Delta^{\alpha}\left(f(x)-f\left(x_{0}\right)\right)}{\left(x-x_{0}\right)^{\alpha}}
\end{aligned}
$$

for $0<a \leq 1$ where

$$
\begin{aligned}
& \Delta^{\alpha}\left(f(x)-f\left(x_{0}\right)\right) \cong \\
& \Gamma(1+\alpha) \lim _{x \rightarrow \infty} \Delta\left(f(x)-f\left(x_{0}\right)\right)
\end{aligned}
$$

And local fractional integral of $f(x)$ defined by Eq.3.

$$
\begin{aligned}
& { }_{a} I_{b}^{(\alpha)} f(t)=\frac{1}{\Gamma(1+\alpha)} \int_{a}^{b} f(t)(d t)^{\alpha} \\
& =\frac{1}{\Gamma(1+\alpha)} \lim _{\Delta t \rightarrow 0} \sum_{j=0}^{j=N-1} f\left(t_{\mathrm{j}}\right)\left(\Delta t_{\mathrm{j}}\right)^{\alpha}
\end{aligned}
$$

With $\Delta t_{j}=t_{j+1}-t_{j}$ and $\Delta t=\max \left\{\Delta t_{1}, \Delta t_{2}, \cdots, \Delta t_{j}, \cdots\right\}$, where for $j=1,2, \cdots, N-1,\left[t_{j}, t_{j+1}\right]$ is a partition of the interval $[a, b]$ and $t_{0}=a, t_{N}=b$.

If $f(x)$ is defined on the real line $-\infty<x<\infty$, its local fractional Hilbert transform, denoted by $f_{x}^{H, \alpha}(x)$ is defined by

$$
\begin{aligned}
& H_{\alpha}\{f(t)\}=\hat{f}_{H}^{\alpha}(x) \\
& =\frac{1}{\Gamma(1+\alpha)} \int_{R} \frac{f(t)}{\Gamma t-x)^{\alpha}}(d t)^{\alpha}
\end{aligned}
$$

Where $x$ is real and the integral is treated as a Canchy principal value, that is,

$$
\begin{aligned}
& \frac{1}{\Gamma(1+\alpha)} \int_{R} \frac{f(t)}{\Gamma t-x)^{\alpha}}(d t)^{\alpha} \\
& =\lim _{\varepsilon \rightarrow 0}\left[\frac{1}{\Gamma(1+\alpha)} \int_{-\infty}^{x-\varepsilon} \frac{f(t)}{(t-x)^{\alpha}}(d t)^{\alpha}+\right. \\
& \left.\frac{1}{\Gamma(1+\alpha)} \int_{x+\varepsilon}^{\infty} \frac{f(t)}{(t-x)^{\alpha}}(d t)^{\alpha}\right]
\end{aligned}
$$

To obtain the inverse local fractional Hilbert transform, write again Eq. (4) as

$$
\begin{aligned}
& \hat{f}_{H}^{\alpha}(x)=\frac{1}{\Gamma(1+\alpha)} \int_{-\infty}^{\infty} \frac{f(t)}{(t-x)^{\alpha}}(d t)^{\alpha} \\
& =\frac{1}{\Gamma(1+\alpha)} \int_{-\infty}^{\infty} f(t) g(x-t)(d t)^{\alpha} \\
& =f(x) * g(x), \\
& g_{i}(x)=\alpha_{i} k_{1 i}(x)+(1-\alpha) k_{2 i}(x), \alpha \in(0,1) \\
& \overrightarrow{\mathrm{y}}=\left[y_{1}, y_{2}, y_{3}, \ldots, y_{N}\right]^{T} \\
& \overrightarrow{\mathrm{e}}=\left[e_{1}, e_{2}, e_{3}, \ldots, e_{N}\right]^{T} \\
& \vec{\omega}=\left[\omega_{1}, \omega_{2}, \omega_{3}, \ldots, \omega_{N}\right]^{T} \\
& \overrightarrow{\mathrm{G}}=\left[\mathrm{g}_{1}, g_{2}, g_{3}, \ldots, g_{N}\right]^{T} \\
& \mathrm{~g}_{\mathrm{k}}=\left[\mathrm{g}_{\mathrm{k}}\left(x_{1}\right), \mathrm{g}_{\mathrm{k}}\left(\mathrm{x}_{2}\right), \mathrm{g}_{\mathrm{k}}\left(\mathrm{x}_{3}\right), \ldots . ., \mathrm{g}_{\mathrm{k}}\left(x_{N}\right)\right]^{T}
\end{aligned}
$$

\section{THE RESEARCH-BASED LEARNING TEACHING MODEL IN "NETWORK MARKETING" COURSE APPLICATION}

"Network Marketing" is developing rapidly in recent years, based on the theory of traditional marketing on a combination of modern network technology and information technology for an emerging interdisciplinary marketing management, financial network technology, information science, disciplines of marketing, economics, management, law, etc. as a whole. Currently, many colleges and universities in the "Network Marketing" course teaching basic to marketing theory, basic knowledge of the core content, combined with the characteristics of network marketing through lectures and practical training to enable students to truly master the basic concepts, principles and methods while closely the actual market situation and business-specific marketing environment, so realistic, practical, targeted unity.

In the past, teaching activities, teachers are teaching organizer, leader and facilitator, students in a passive position, "cramming" Teaching was once dominant. Teaching students in the passive model of learning, easy to form unrealistic expectations, on paper, the theory divorced from reality habits. Any one discipline is derived from practice, and practice varies with the change, "network marketing" is no exception. In China, since the market began to network, network policy has been in the consumer market changes, the company's marketing environment is also changing. Especially in recent years, with the increase of China's Internet users and raise 
consumer awareness and consumption of network capacity, network marketing business demand for talent has increased dramatically; Jobs became one of the most popular websites in many professional, but also found that recruitment companies to network marketing professionals in terms of professional quality is difficult to meet the needs of enterprises, universities also found that the old teaching philosophy and teaching methods no longer meet urgent social reform and development, and professional courses.

In this model, teachers should not only teach students basic knowledge of marketing theory, but also to develop students' thinking ability and practical ability. Schools should be oriented to the needs of students, according to student demand for professional, to take student satisfaction teaching methods to improve teaching conditions, innovative teaching model, and students to strengthen two-way communication. Specific to the classroom, the teacher must first consider how students learn, in-depth study of the psychological characteristics and thinking law students, the creation of autonomous learning environment, stimulate students' motivation to learn, grasp this opportunity to optimally promote independent learning. For example, the creation of an objective to explore scenarios, are including a variety of experimental conditions, intuitive situations, such as natural context and social context. You can also create mental scenarios, including a variety of problem situations and so on. Teachers need to study the characteristics of students, to find the best combination of old and new knowledge, setting the problem situation, to promote the rapid assimilation of new knowledge on existing knowledge structure, comprehensive observation and hands-on training with capable people.

The computer network experiment is to develop student's ability to observe, an important part of ability and experimental skills. In experiments on experimental teaching content and schedule, is to try to synchronize content with theoretical lessons so that students in a timely manner to consolidate the theoretical knowledge learned in the classroom, so that theory and practice closely. Emphasis on schoolenterprise cooperation, at the start of the course, the students of the course to enterprise awareness training, a number of companies on the internet network marketing strategies preliminary analysis; secondly, at the end of the course to enterprise summative practice. Teachers should be based on the teaching material goals, looking closely associated with the teaching content can stimulate students' interest, the creation of a specific situation, the students were asked to study the field, to guide students to discover and explore the issues raised need to fully mobilize students to learn autonomy. Only carry out the practice of teachers and students as the centre of philosophy of education, improve the practical teaching system, in order to truly meet the needs of the community to cultivate talent.

\section{CONCLUSION}

The talent standard of business need is changing, with the development of economy and changes of market environment. As a community college professional training as the main front in the teaching model and teaching concepts must advance with the times, according to market demand, changes in the environment to make adjustments, effective and timely introduction of advanced educational concepts and practices and advanced teaching. The only way to cultivate more excellent for the social is usefulness of talent.

\section{CONFLICT OF INTEREST}

The author confirms that this article content has no conflict of interest.

\section{ACKNOWLEDGEMENTS}

This work is supported by the Key Project of Guangxi Social Sciences, China (No. gxsk201424), the Education Science fund of the Education Department of Guangxi, China (No.2014JGA268), and Guangxi Office for Education Sciences Planning, China (No.2013C108).

\section{REFERENCES}

[1] G. Charles, "Morris contemporary psychology and effective behavior", (7thed.), Scott, Foresman and company Press, 1990.

[2] S. Cui, "Research on the Improving Path of College Student Employability from Social Practice Perspective", Journal of Applied Science and Engineering Innovation, vol. 2, no. 3, pp. 81-83, 2015.

[3] C. Dantzig, and J. Ramser, "The truck dispatching problem", $M a-$ nagement Science, vol. 10 no. 6, pp. 80-91, 1959.

[4] D. Court, "Studying teacher's values, the annual editions", Education, 1993/94, The dushkin Publishing Group,Inc Press, 1993.

[5] D. Plunkett, "Secular and spiritual values: grounds for hope in education", Routledge, London Press, 1990.

[6] P.H Hanus, "Educational aims and educational values", N.Y., London, the Macmillan Co. Press, 1911.

[7] J. S. Brubacher, "The public school and spiritual values, harper and brothers publishers", N.Y. and London Press, 1946.

[8] M. B. Marks, J. K. Lemlech, "As a study of values for the metropolitan teacher", The Journal of the Association of Teacher Educators, vol. 9,no. 3, Fall Press, 1987.

[9] D. Richard, V. Scotter, "Socail foundations of education", Prentice-hall Inc. New Jersey Press, 1991.

[10] Ruhela, SatyaPal, ed: Human Values and Education, New Delhi Press, 1986.

[11] N. B. Tarrow, "Human Rights and Educantion", Oxford, Pergamon Press, 1987.

[12] W. Bagley, "Edcational values", The MacMillan Company, New York, 1912.

[13] L.E. Burke, and J. Fair, J. "Promoting prevention: skill sets andattributes of health care providers who deliver behavioral interventions", Journal of Cardiovascular Nursing, vol. 18, pp. 256-266, 2013.

[14] M.B. Potter, J.D. Vu, and M. C. Minihane, "Weight management: What patients want from their primary care physicians", The Journal of Family Practice, vol. 50, pp. 513-518, 2011.

[15] O. Sibel,'Food safety education makes the difference food safety perceptions, knowledge, attitudes and practices among turkish university students", Journal for Verbraucherschutz and Lebensmittelsicherheit, vol. 6, pp. 25-34, 2010.

Received: June 10, 2015

Revised: July 29, 2015

Accepted: August 15, 2015

(C) Yanni Li; Licensee Bentham Open.

This is an open access article licensed under the terms of the (https://creativecommons.org/licenses/by/4.0/legalcode), which permits unrestricted, noncommercial use, distribution and reproduction in any medium, provided the work is properly cited. 